\title{
AIDS physicians find support in the trenches
}

Patients with terminal diseases such as AIDS frequently attend support groups to help them cope with their disease, as do their families and friends. But what about the physicians who care for these patients? For them, seeing that pain, suffering, and inevitable death is the norm, remaining emotionally detached from their patient and his or her struggle is almost an impossibility. Thus it is no surprise that once a month in Dallas, Texas, seven physicians (several of whom are HIV-infected themselves or whose spouses are infected) gather to talk about their experiences and emotions in dealing with AIDS in a support group for physicians. What is surprising is that it may be the only one of its kind.

The Dallas support group originally formed almost seven years ago, a time when less was known about AIDS and its transmission than now, and a time when few, if any, effective medications were available. The feeling of helplessness in the face of the AIDS plague was pervasive among physicians who had limited knowledge and few options for treatment. After one of his patients found out that he was positive for the HIV virus and hanged himself, a physician in private practice brought the idea for a support group to several psychologists who were interested in working with AIDS patients. "Initially the group came together to support each other because there was such a small community working with HIV and AIDS, and they used it to trade information," says Stacy Broun, a psychologist at Southwestern Medical School in Dallas who coleads the support group. Members of the group seldom discuss treatment now, choosing instead to deal with more emotional and personal issues, including the deaths of two group members' spouses from AIDS.

One of the original physician members of the group, Alan Hamill (who is now retired from private practice as a physician because he is in the end stages of AIDS), says that participating in the support group has benefited him "phenomenally." Hamill feels that it helped him to treat and empathize with his patients better. "It's been a very useful tool in just understanding how others cope, to allow me to cope better myself," he says, "I have actually shortened trips and tried to arrange my travel plans so that I could be here for [the meetings]. It's re- ally come to mean a lot [to] me."

Another member of the group, Jose Garces, has cared for AIDS patients for almost ten years. Garces, who works in a Dallas public clinic, says that the support group helps him to manage the type of patients he sees in his practice (more than 50 percent of the patients he has seen have died from AIDS, many of them at a very young age). "Health-care providers and physicians explicitly are very well known for not really taking care of ourselves," he says. Garces believes the group provides its members with the opportunity to do this, which he believes is essential "in this intense and complicated field."

It seems logical that working with AIDS patients (where physicians "don't have the luxury of going home and dropping this and turning on the TV," notes Broun) would require a place for physicians to express their emotions and benefit from a support system. However, despite lecturing about the Dallas support group internationally, neither Broun nor the other physicians in the group are aware of any other physician support groups of this kind. Broun suggests that this lack may be due, in part, to "a persona that goes along with being a doctor; that you know everything, that you're god-like, and you can take care of everything including yourself." Angela Kavas, a psychologist at Kaiser Permanente and in private practice, and coleader of the group, agrees. "The world thinks that physicians can handle everything and that's what they're taught to do," she says, "I think what we've been able to do is let physicians know that that's not what the world has to - or should expect." Others suggest another reason that such support groups may not be more common: doctors are just too busy. "It's hard as hell to get doctors together unless there's a free meal involved," says Hamill.

According to Garces, the medical community has responded positively to the group. "All physicians and other health care providers that $I$ know and have come in contact with are extremely pleased that we have such a group and welcome the idea and actually state implicitly that this should be done much more frequently," he says. Garces believes that a shift in attitude may be necessary, for established practicing physicians as well as medical school students and instructors, for this to become a reality. "I don't think we're taught enough explicitly that we [physicians] too have the need for nurturing and emotional support," he says.

As the number of AIDS cases continues to rise, and physicians continue to bear the emotional and physical burdens of watching their patients suffer and die, hanging on to a hope for more and better treatment options, or even a cure, may not be the only way to fight back. Support groups such as the one in Dallas will not win the battle against terminal diseases like AIDS, but they may make it more manageable for now.

IRIS KEDAR Washington, $D C$ 